\title{
Climate change and developing country growth: the cases of Malawi, Mozambique, and Zambia
}

\section{Channing Arndt ${ }^{1}$ (D) Paul Chinowsky ${ }^{2} \cdot$ Charles Fant $^{3} \cdot$ Sergey Paltsev $^{4}$ • C. Adam Schlosser ${ }^{4} \cdot K_{\text {Kenneth Strzepek }}^{4} \cdot$ Finn Tarp $^{5}$ • James Thurlow ${ }^{6}$}

Received: 13 March 2017 / Accepted: 26 March 2019 / Published online: 23 April 2019

(C) The Author(s) 2019

\begin{abstract}
We consider the interplay of climate change impacts, global mitigation policies, and the economic interests of developing countries to 2050. Focusing on Malawi, Mozambique, and Zambia, we employ a structural approach to biophysical and economic modeling that incorporates climate uncertainty and allows for rigorous comparison of climate, biophysical, and economic outcomes across global mitigation regimes. We find that effective global mitigation policies generate two sources of benefit. First, less distorted climate outcomes result in typically more favorable and less variable economic outcomes. Second, successful global mitigation policies reduce global fossil fuel producer prices, relative to unconstrained emissions, providing a substantial terms of trade boost of structural fuel importers. Combined, these gains are on the order of or greater than estimates of mitigation costs. These results highlight the interests of most developing countries in effective global mitigation policies, even in the relatively near term, with much larger benefits post- 2050 .
\end{abstract}

\section{Introduction}

We consider the interplay of climate change impacts, global mitigation policies, and the economic interests of developing countries to 2050. The analytical focus is on three case countries: Malawi, Mozambique, and Zambia - all countries containing the Zambezi river basin (ZRB) as a prominent physical feature. While case studies have well-known limitations in terms of their ability to generalize results, the detail afforded in case studies can provide new insights. The framework employed here underpinned a special issue of Climatic Change, which focused on impacts and adaptations in the same three countries to 2050 mainly under an unconstrained global emissions (UE) regime (Arndt and Tarp 2015).

Electronic supplementary material The online version of this article (https://doi.org/10.1007/s10584-01902428-3) contains supplementary material, which is available to authorized users.

Channing Arndt

c.arndt@cgiar.org

Extended author information available on the last page of the article 
Here, we focus on comparing economic outcomes from the UE regime with those from a strict global emissions regime (labeled L1S) that succeeds in capping atmospheric concentrations of greenhouse gases to about $560 \mathrm{ppm} \mathrm{CO} 2 \mathrm{eq}$ using the same framework. ${ }^{1}$ Comparisons of distributions of economic outcomes across global mitigation regimes have never, to our knowledge, been rigorously conducted for low-income countries. The modeling produces an estimate of the relatively short run (to about 2050) benefits of ambitious and effective global mitigation, relative to unconstrained emissions, for the three countries in focus assuming these developing countries are exempted from the global mitigation regime.

We find that effective global mitigation policies generate two sources of benefit by 2050 . First, under effective mitigation, the distribution of future climate outcomes is characterized by mean and mode values closer to historical norms with reduced variance compared to a scenario with unconstrained emissions globally. These less distorted climate outcomes result in typically more favorable biophysical and economic outcomes. In all three countries, the mean and mode of the distribution of gross domestic product (GDP) in about 2050 shift to the right (favorably) and the variance declines under successful mitigation.

Second, successful global mitigation policies can be expected to reduce fossil fuel prices, relative to the case of unconstrained emissions (Bauer et al. 2016; Paltsev 2012; Carney 2015). The fundamental reasons for these price declines were succinctly set forth by Mark Carney during his tenure as Governor of the Bank of England. IPCC (2014) estimates a carbon budget that would limit global temperature rises to $2{ }^{\circ} \mathrm{C}$ above pre-industrial levels. This budget corresponds to burning between $1 / 5$ th and $1 / 3$ rd of the world's proven reserves of oil, gas, and coal. As noted by Carney, "if that estimate is even approximately correct, it would render the vast majority of reserves 'stranded' - oil, gas and coal that will be literally unburnable without expensive carbon capture technology, which itself alters fossil fuel economics" (Carney 2015). The three case countries considered here, like nearly all low-income countries and most middle-income countries, are structural importers of fossil fuels. ${ }^{2}$ Reduced global producer prices of fuels confer substantial terms of trade gains (Arndt et al. 2012b).

The sum of these two gains vary by case country but are mainly greater than $1 \%$ of GDP and range above $7 \%$ in the case of Mozambique. These gains are roughly equivalent to or greater than the global welfare costs associated with mitigation to about $550 \mathrm{ppm} \mathrm{CO} 2 \mathrm{eq}$ of about 1.2 to $3.3 \%$ presented in the Fifth Assessment Report (Edenhofer et al. 2014). ${ }^{3}$ Gains associated with a stabilized climate can be expected to be much greater in the second half of the twenty-first century (Field et al. 2014). We conclude that the case countries considered have clear interests in seeing effective global mitigation policies enacted, even over relatively short time frames. As the drivers of these results are fairly general, this conclusion likely pertains to many other developing countries.

\footnotetext{
${ }^{1}$ Global temperature implications of the L1S emission regime are explored in Webster et al. (2012), where it is labeled as "Level 1." This regime results in limiting the change in annual mean surface temperature to $1.6^{\circ} \mathrm{C}$, when measured as decadal average of 2091-2100 relative to 1981-2000.

${ }^{2}$ Mozambique has discovered substantial gas and coal reserves and is currently organizing to exploit these reserves at scale. For a host of reasons explained in supplementary appendix B, the implications of these resource finds are ignored in this analysis. Hence, the forward-looking Mozambique results refer to a scenario where resource exploitation does not occur.

${ }^{3}$ Due to rapid technical advance in renewable energy and battery technologies, estimated costs of global mitigation are declining. For example, the recently released $1.5^{\circ}$ report from the IPCC states: "All renewable energy options have seen considerable advances over the years since AR5, but solar energy and both onshore and offshore wind energy have had dramatic growth trajectories. They appear well underway to contribute to $1.5^{\circ} \mathrm{C}$ consistent pathways" (IPCC 2018, p. 4-17).
} 
The remainder of this article is structured as follows. Section 2 compares our results with existing literature. Section 3 reviews the methods employed. Section 4 considers outcomes for the following: temperature and precipitation; world commodity prices with an emphasis on fuels; biophysical outcomes with an emphasis on runoff; and economic outcomes with a focus on GDP in about 2050. In all cases, outcomes between a scenario characterized by unconstrained emissions (UE) and a scenario characterized by successful global mitigation policy that stabilizes atmospheric concentrations to about $560 \mathrm{ppm}$ CO2eq (L1S) are compared. The final section discusses implications for developing countries.

\section{Literature review}

The implications of mitigation policies for developing countries to 2050 have only been lightly researched. The most prominent study is Hasegawa et al. (2018) who present a multi-model analysis of the implications of climate change for food insecurity. They conclude that strict mitigation policies may increase the risk of food insecurity out to about 2050. The authors point to three principal mechanisms driving this result. First, emissions restrictions are applied globally including agricultural activities. These restrictions reduce production hence increasing food prices. Second, climate change impacts by 2050 are small relative to those expected by 2100 under unconstrained emissions. Hence, the benefits of mitigation policies for agricultural production and food security are relatively small. Third, mitigation policies catalyze broadscale shifts towards bioenergy. Production of bioenergy feedstocks competes with food production for land, water, and other resources, driving up food prices again.

In this article, the focus of presentation is on GDP; nevertheless, the food security results are broadly consistent with the GDP results. In our approach, stringent mitigation does not systematically exacerbate food security to 2050 relative to an unconstrained emissions scenario. There are a series of reasons why results differ. First, Hasegawa et al. (2018) impose mitigation requirements on all countries, including low-income countries, while this analysis exempts the case countries.

Second, while Hasegawa et al. (2018) rely on a suite of models with different structures, it is broadly the case that, in those models, higher food prices necessarily decrease food security. This second point merits elaboration as it is a main mechanism driving the deterioration in food security obtained by Hasegawa et al. (2018). As pointed out by Headey and Martin (2016), the stimulus to agriculture provided by higher food prices has the potential to increase purchasing power for the rural poor sufficiently to outweigh the negative impacts of higher food prices via a general stimulus to the rural economy. If most poor people reside in rural areas, then higher food prices could improve food security in the aggregate.

The sustained food price rise that characterized the period 2004-2014 provides some empirical evidence. The best available evidence indicates that sustained increases in food prices (as opposed to temporary shocks) improved food security on average (Headey 2018; Headey and Martin 2016). Whether this will continue to be the case in 2050 depends upon demographics and economic structure (Hertel 2015). Overall, the models employed in this article are much better suited to capturing these rural/urban terms of trade effects than those employed by Hasegawa et al. (2018).

Third, the global models employed in Hasegawa et al. (2018) either exclude energy prices (notably oil) entirely or operate at aggregate levels that combine importers with exporters. For example, treating sub-Saharan Africa as a single economic region could be caricatured as 
South Africa with oil (from Nigeria, Angola, and elsewhere). Terms of trade effects from oil prices are thus either ignored entirely or diluted substantially by aggregating importers and exporters together even though most low- and lower-middle-income countries are decidedly either net fuel importers or net fuel exporters.

Finally, the modeling here typically includes a greater number of impact channels allowing for greater scope for mitigation to yield improved outcomes. Overall, the case study approach applied here has significant advantages and should serve as a useful complement and crosscheck to more global analyses.

\section{Methods}

The approach employs a chain of modeling frameworks whose principal components and flows are described in Fig. 1. It starts with the Integrated Global Systems Model (IGSM) in the top box labeled "Global Change" (Sokolov et al. 2005). The IGSM consists of three primary components:

(1) Economics, emissions, and policy cost component for analysis of human activities, including policy measures, as they interact with climate processes;

(2) Climate and Earth system component: coupled dynamic and chemical atmosphere, ocean, land, and natural ecosystem interactions and feedbacks; and

(3) Land ecosystems and biogeochemical exchanges component, within a global land system framework, for analysis of the terrestrial biosphere.

The economics component is represented by the Emissions Prediction and Policy Analysis (EPPA) model, which is a relatively detailed dynamic computable general equilibrium model of the global economy (Paltsev et al. 2005). The EPPA model provides economically coherent emissions projections based on detailed structure of domestic production, consumption, and international trade as well as evolution of advanced technologies, depletion of fossil-fuel resources, land requirements, and population growth among other items. In addition, policies to reduce emissions or target particular emissions rates can be imposed on the model. As a result, EPPA generates global price paths for fossil fuels (coal, oil, and natural gas), alongside other commodities, in accordance with the selected policy regime (Paltsev 2012).

In order to rigorously explore uncertainties in the underlying climate and human processes, the IGSM is purposely built as a model of intermediate complexity. Relatively light computational burdens imply that the IGSM can be solved repeatedly across an array of crucial parameter values relating to all three primary components. By specifying joint distributions for key parameters and drawing points from these distributions (Sobol Monte Carlo is employed), hybrid frequency distributions (HFDs) of climate outcomes can be generated and analyzed conditional on a global mitigation policy regime (Webster et al. 2012). As such, the IGSM represents one of the first and most detailed attempts to characterize the distribution of future climate outcomes.

The drive to characterize a distribution of future climates comes at the cost of regional detail. On its own, the IGSM generates only zonal outputs (outputs by latitude band). Schlosser et al. (2013) propose an approach to develop regional hybrid frequency distributions of climate outcomes. This approach is operationalized by Schlosser and Strzepek (2015). In the approach, 


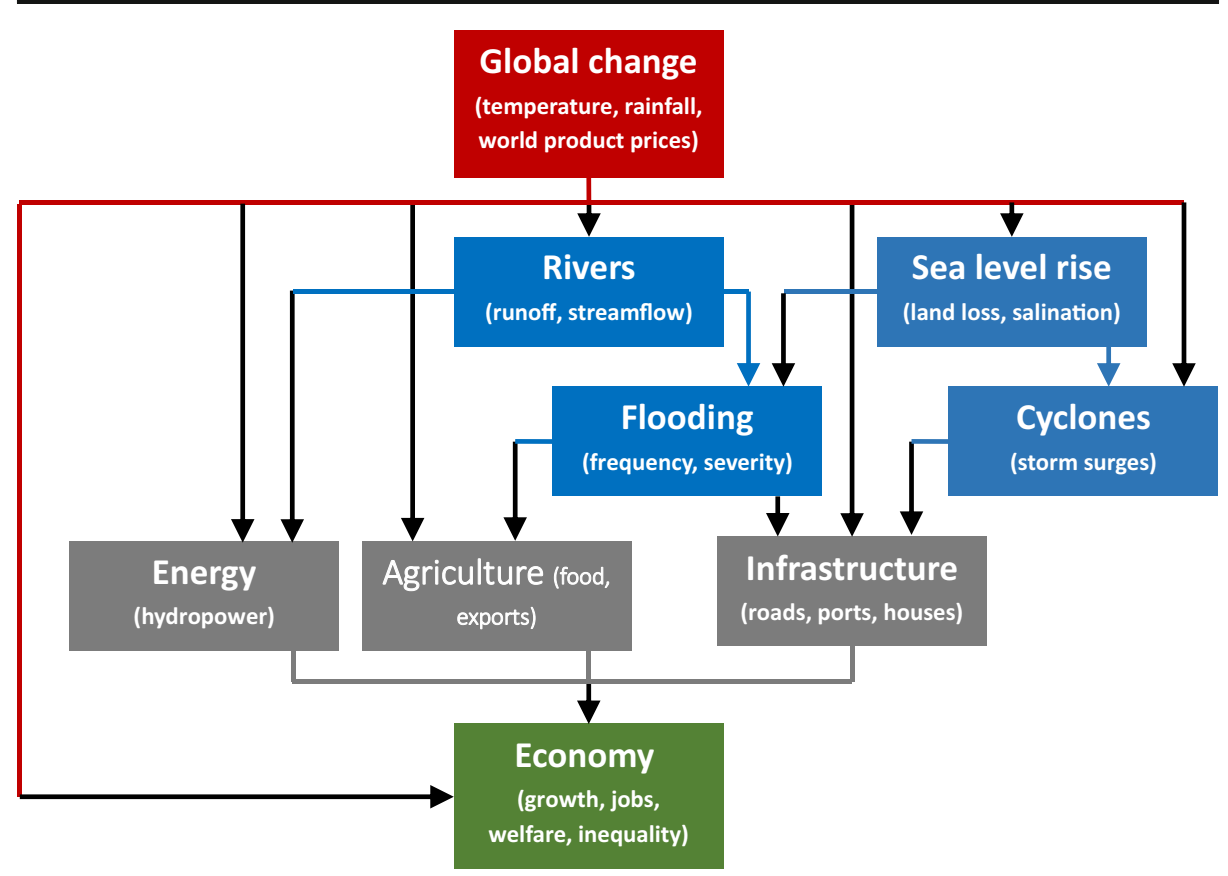

Fig. 1 Schemata of analytical framework

projections of regional changes in surface-air temperature and precipitation were developed by combining outputs from the IGSM with pattern-change kernels from climate-model results of the Coupled Model Inter-Comparison Project (Meehl et al. 2007).

The approach of Schlosser and Strzepek (2015) produces a distribution containing 6800 potential future climates for the entire Southern Africa region. For the purposes of detailed biophysical and economic analysis, computations involving 6800 climates are burdensome. Arndt et al. (2015) develop an approach, rooted in the numerical integration literature, to intelligently choose a weighted subset of approximately 400 climates for detailed analysis.

Runoff is modeled using a variant of the CliRun modeling framework, which is based on an approach first proposed by Kaczmarek (1993). Agricultural yields and irrigation water demands were assessed based on a variant of the CliCrop model (Fant et al. 2012). Results from these models serve as inputs into a water resources systems model, based on the approach of Sieber and Purkey (2007), for assessment of flood risk, hydropower output, and balancing of water supply and demand across competing uses. Fant et al. (2015) describe the application of this modeling suite (CliRun, CliCrop, and water resources) to the countries in focus.

Sea level rise and cyclone strike apply only to Mozambique. Neumann et al. (2013) describe the approach employed for assessing these risks.

Chinowsky et al. (2015) model implications for infrastructure with particular emphasis on roads. A variant of their infrastructure model is directly incorporated into the economy-wide model, depicted at the bottom of Fig. 1, in the manner described in Arndt et al. (2012a).

Country-level economy-wide models, one each for Malawi, Mozambique, and Zambia, aggregate the impacts derived from the various biophysical models described above within the context of a market economy. As discussed in Arndt and Thurlow (2015), this modeling approach has the dual advantages that (i) it respects all macroeconomic constraints and (ii) it is 
detailed permitting, for example, differential implications of climate change for the same crop by region within a country.

The modeling framework employed arguably represents one of the more detailed and advanced efforts ever applied to developing countries. ${ }^{4}$ The modeling philosophy seeks to create plausible mathematical representations of the most prominent and relevant biophysical and economic characteristics of the case countries. These representations are then exposed to sets of future climates, 426 climates for the UE scenario and 398 for the L1S scenario, that represent the best available estimation of the distribution of future climates to 2050 by emissions stabilization scenario. These distributions of climate outcomes are obtained from the models at the top of Fig. 1 in the box labeled "Global Change." All subsequent models below "Global Change" are run for each climate scenario. The modeling framework thus produces distributions of climate, biophysical, and economic outcomes by emissions stabilization scenario.

Comparison of these distributions across global emissions scenarios is in focus in the discussion of results. For purposes of clarity, distributions of biophysical results and economic analysis of the unconstrained emissions scenario, drawn from the aforementioned special issue of Climatic Change, are reviewed (Arndt and Tarp 2015). Comparison of economic outcomes across mitigation scenarios is new and is the focus of the analysis.

\section{Results}

For purposes of presentation, the climate (Section 4.1) and biophysical (Section 4.3) results focus on the Zambezi River Basin (ZRB). Economic analysis is conducted at the country level for each of the three cases.

\subsection{Climate outcomes}

We find notable differences in climate outcomes between the unconstrained emissions (UE) and the mitigation scenario (L1S) for the ZRB as a whole by 2050. Schlosser and Strzepek (2015) provide a detailed description of the results obtained for sub-regions of the ZRB. Here, we focus on precipitation in the planting season and temperature in the summer (warmest months) as these are the most important for dry land agriculture. Frequency distributions of planting season (September-November, SON) precipitation change are shown in Fig. 2 (left panel). In the UE scenario, the mode of the distribution of precipitation shifts towards drier outcomes, although both substantial increases and decreases in precipitation are possible. Under L1S climate policy, the range of outcomes is reduced. Notably, the most extreme drying outcomes (decreases of $-0.5 \mathrm{~mm} /$ day and higher) are removed. Nevertheless, even under L1S, precipitation remains likely to decrease, with $42 \%$ of the L1S distribution at or below a decrease of $-0.2 \mathrm{~mm} /$ day in planting season (SON) precipitation.

For surface-air temperature (Fig. 2, right panel), the L1S scenario reduces the modal value of the summer (December-February, DJF) temperature-change distribution by at least $1{ }^{\circ} \mathrm{C}$ (less warming), with $56 \%$ of the distribution within a $1-1.5^{\circ} \mathrm{C}$ increase in summer temperature - contrasted by nearly $56 \%$ of the UE distribution spanning summer temperature increases

\footnotetext{
${ }^{4}$ Time steps differ across these models. EPPA works on a 5-year time step while the climate components of the IGSM are hourly. CliCrop requires daily inputs while CliRun works on a monthly time step.
} 

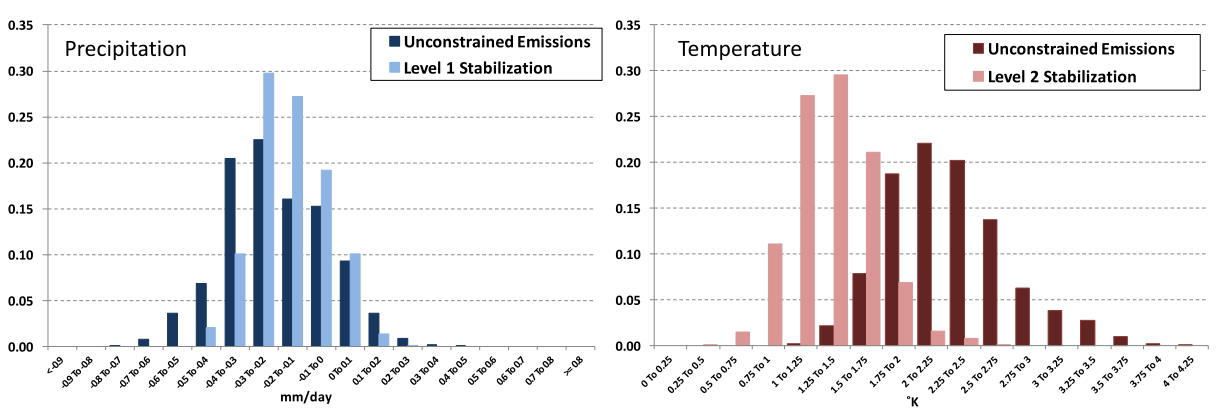

Fig. 2 Hybrid frequency distributions (HFDs) obtained from the IGSM simulations of changes in decadalaverage seasonal precipitation for September-November (left panel) and decadal-averaged seasonal surface-air temperature change for December-February (right panel). Decadal average changes are taken as average of 2040s minus average of 1990s. The changes represent area-averaged values for the Zambezi River basin. Results are shown for an unconstrained (darker shaded bars) and the level 1 stabilization scenario (lighter shaded bars) ensemble simulations with the IGSM. Ordinate values indicate the fraction of the ensemble members that are contained within the binned seasonal precipitation and temperature changes

exceeding $2.5^{\circ} \mathrm{C}$ (relative to an end of twentieth century average). Similar to what we show for precipitation, strong mitigation eliminates the occurrences of the most extreme temperature increases and shifts the distribution leftward. Specifically, the upper half of the UE distribution of change (exceeding $2.5^{\circ} \mathrm{C}$ warming) is excluded in the L1S range of occurrences. Additionally, we find that the minimum warming in the distributions is less affected, indicating that even in the very aggressive mitigation scenario considered for this study, some degree of climate warming, combined with changes in precipitation, is likely unavoidable.

\subsection{Global fossil fuel prices}

The prices of fossil fuels are determined by the supply and demand for fossil fuels, considering interactions with alternative fuels that can act as substitutes. As fossil fuel resources deplete, the cost of production for additional resources tends to rise tempered by gains in extractive technologies. Technological progress also has implications on the demand side through improvements in energy efficiency. Figure 3 shows indices of world producer prices for coal, oil, and natural gas. The indices are constructed as a ratio of the price in the climate policy scenario (L1S) relative to the price in the unconstrained emissions scenario (UE). ${ }^{5}$ For illustrative purposes, the figure extends to 2100 even though the focus of our analysis is to 2050 .

The L1S climate policy lowers producer prices relative to UE due to a reduction in oil demand and competition from biofuels. Substantial margins between the cost of production and sale prices result in large price reductions as oil producers try to minimize oil demand reductions. By about 2050, oil prices that producers receive are lower by $60 \%$ in the L1S scenario in comparison to UE. This difference grows to almost $80 \%$ by the end of the century.

Coal producers also face price decreases under the climate policy, but most of them are already producing close to their marginal costs; therefore, they are not able to reduce their margins. Instead, carbon policies drastically reduce demand for (and production of) coal with some revival when carbon capture and storage (CCS) technology become economic. By 2050

\footnotetext{
${ }^{5}$ Fossil fuel prices move significantly in the short and medium terms due to a host factor affecting supply and demand. The modeling here abstracts from these movements and concentrates on the ratio of fuel prices between the L1S and UE scenarios.
} 


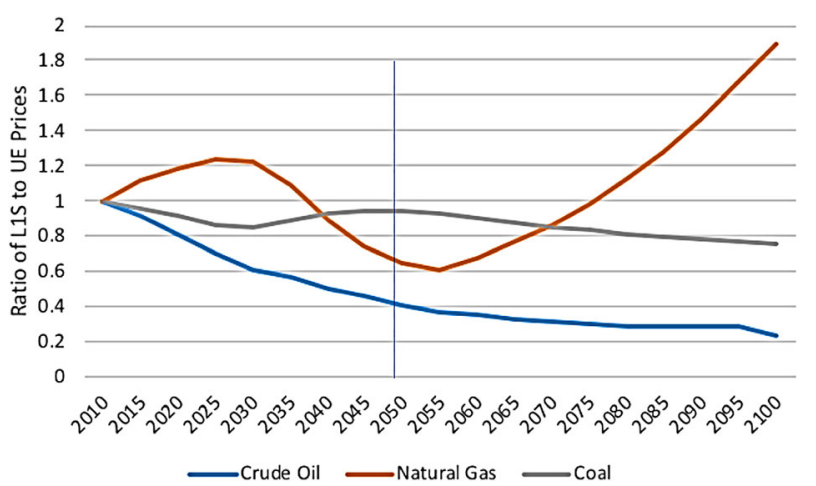

Fig. 3 Index ratio of fossil-fuel producer prices (net of carbon charge) in a climate policy scenario (L1S) relative to the unconstrained emissions scenario (UE)

and 2100 , coal prices that producers receive are lower by about $10 \%$ and $25 \%$, respectively, in L1S compared with UE (Paltsev 2012).

Natural gas price dynamics are more complicated. There are three segments. In the first segment, L1S prices are higher than in the UE scenario due to a switch from coal to natural gas. In the second, tighter emissions targets make natural gas less attractive as it still emits carbon, and there is a need to move to even lower carbon-emitting technologies such as wind, solar, and bioenergy. In the third, two factors serve to push up the price of natural gas relative to UE. The first factor is the large shares of renewables entering the power generation mix. Natural gas producer prices rise (relative to UE) because natural gas serves as a means to resolve intermittency issues. This is the smaller of the two factors. Natural gas is also used with CCS in the second half of the century, which is the larger factor.

The key result, which is qualitatively very similar to the result obtained by Bauer et al. (2016), ${ }^{6}$ is that the price of the most traded fossil fuel, oil, is significantly lower under the L1S policy regime compared with UE. Global emissions policies also cause changes in the prices of other commodities, such as agriculture. However, the relative price shifts are much less pronounced.

\subsection{Runoff}

Runoff supplies rivers and reservoirs with surface water. Increases in runoff imply that more surface water is available for various uses, including irrigation and hydropower production, although this availability also depends on water resource management as well as available storage and diversion. Decreases in runoff are likely to result in less water available for irrigation and hydropower production while rapid increases in runoff correlate with flood events. For this reason, runoff is a convenient indicator of how changes in climate translate into changes in water availability, which then affects economic outcomes.

The percent change in mean annual runoff, aggregated from 29 to five major basins, is shown in Fig. 4. The graphs within the figure contain the percentage change on the horizontal axis and the estimated kernel density (a measure of likelihood) on the vertical axis. Below each graph, the baseline mean annual runoff is shown as a proxy for the hydrologic significance of each basin. Also, the 10th and 90th percentiles of the modeled historical period - 1951 to 1990 - are shown in order

\footnotetext{
${ }^{6}$ See supplementary appendix A for additional discussion about the fossil fuel price modeling.
} 
to illustrate the magnitude of the climate scenario results as compared to the inter-annual variability that has been observed over the 40 -year baseline period. The percentage shifts in runoff shown in the graphs represent 10-year means (2041-2050).

For Cahora Basa, the mode from UE and L1S both rest at about zero change and the extremes reach about $\pm 20 \%$ with very little difference between the two policies. The results are similar for the Shire River, although the UE case projects a slightly wetter future, and the overall expectation for both scenarios is also wetter with the mode at about $+5 \%$. In the other three major basins, a decrease in runoff is more likely, at about $-5 \%$ for the mode value, which is about the same for both policy cases. However, the differences between the shapes of the two policy distributions are more prominent for these three major basins. In all cases, the UE distribution is noticeably wider, with more extreme tails, reaching $-50 \%$ for both the Kafue and Upper Zambezi. These two major basins also show a slightly lower expected runoff for the UE than the L1S scenario.

These changes in runoff, along with changes in irrigation demands, are used to model water resource allocations in order to understand how these changes in surface water supply translate to changes in water availability for the various users. We find that the water sector in Malawi is the least sensitive to climate change. Alternatively, Zambia is predicted to experience losses in terms of hydropower generation, caused mostly by expected decreases in runoff in the west, as well as upstream irrigation demands. The impacts on hydropower generation in Mozambique are mild due to a portfolio type effect stemming from a large contributing area. However, large-scale, high-damage flood events are projected to happen more often, especially under UE policy. This result is consistent in qualitative terms with Shongwe et al. (2009) and Hewitson and Crane (2006).

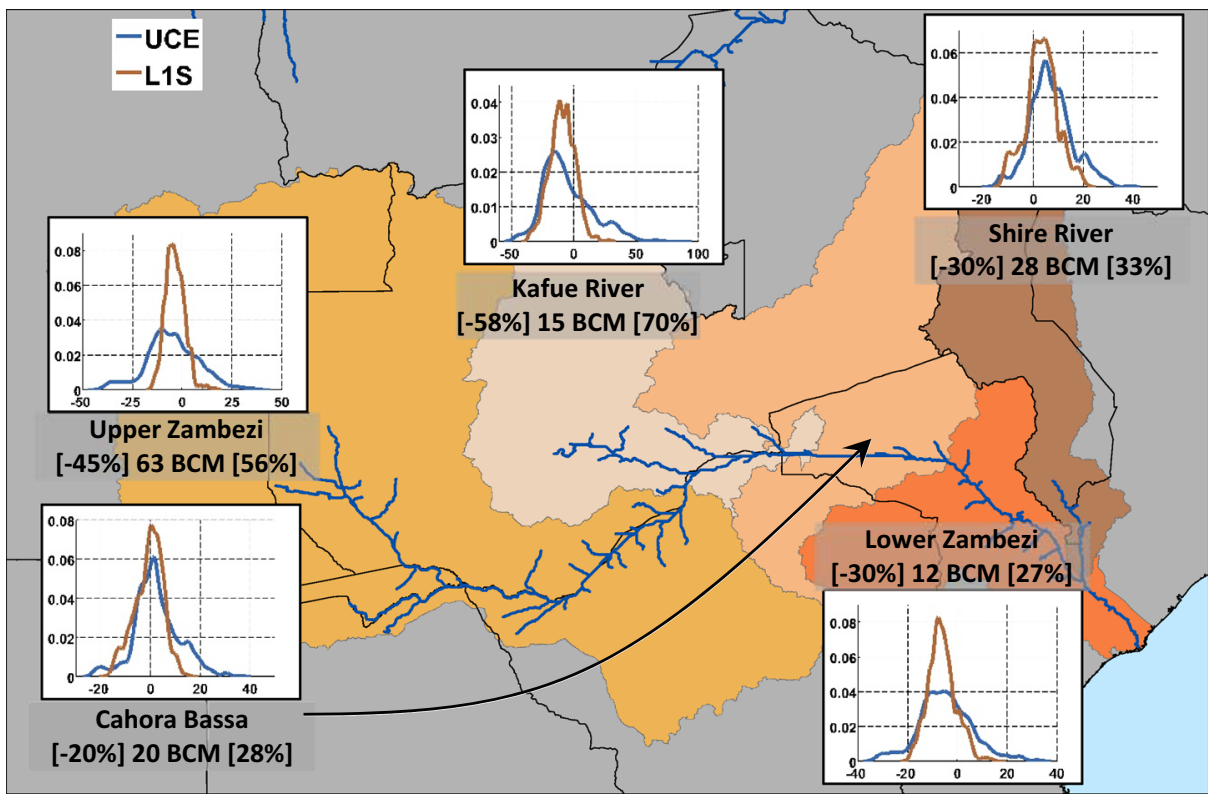

Fig. 4 Climate scenario distribution results of the predicted percent change in runoff for the five major sub-basins of the Zambeze River Valley under unconstrained emissions (UE) in blue and level 1 stabilization (L1S) in red by 2050. The baseline (1951-1990) mean runoff in billion cubic meters (BCM) and the percent difference between the mean and the 10th and 90th historical percentiles are shown below the basin name ([10th] mean [90th]). Source: Fant et al. (2015) 


\subsection{Economic outcomes}

We elect to focus on the distribution of the average level of GDP over the period 2046-2050 for each of the three case countries. These outcomes are illustrated in Fig. 5, where panels a, b, and c correspond to outcomes for Mozambique, Malawi, and Zambia, respectively. For each country, we show three distributions of GDP outcomes corresponding to (i) the unconstrained emissions case, (ii) level 1 stabilization with world prices maintained at levels from the unconstrained emissions case, and (iii) level 1 stabilization with corresponding world prices. The horizontal axis shows the GDP level (average 2046-2050) as compared to a no climate change baseline. The vertical axis presents a measure of likelihood (kernel density estimates) for the associated GDP outcome under climate change.

The sources of GDP losses in the UE scenario relative to the no climate change baseline are discussed in detail in Arndt and Thurlow (2015) for Mozambique and Arndt et al. (2014) for Malawi. Our focus is on comparing the UE with the L1S global policy scenario. Relative to UE, L1S mitigation policy generates two distinct benefits. First, the distribution of economic outcomes shifts notably to the right (favorably) due uniquely to reduced disruption from climate change as a consequence of reduced temperature rise and a reduced likelihood of strong movements in precipitation (shown by the distribution corresponding to L1S climate with UE world prices). The extent of the shift varies by case country. It is most pronounced in Mozambique driven principally by a substantial reduction in flood probabilities (Arndt and Thurlow 2015).

Corresponding to the reduced dispersion of climate outcomes shown in Fig. 1 and biophysical outcomes as in Fig. 4, economic outcomes also tend to be less dispersed under effective mitigation. This is particularly true for the low-income economies, Mozambique and Malawi, where climate-sensitive sectors such as agriculture play a larger role in GDP. Overall, the distributions of economic outcomes in 2050 exhibit higher mean and reduced variance purely as a consequence of less pronounced changes in climate.

Second, like nearly all low-income and most middle-income developing countries, the case countries considered are substantial net importers of fossil fuels, particularly oil and derived products. ${ }^{7}$ The reduced producer prices particularly for oil in the L1S scenario compared with UE scenario (see Fig. 3) generate a gain in terms of trade, which in turn confers substantial benefits in terms of economic growth (and welfare). ${ }^{8}$ In countries participating in the mitigation regime, these terms of trade shifts would be accompanied by the costs of transitioning to less carbon-intensive energy sources. For simplicity and in order to delineate a best-case scenario for our case countries, we present economic outcomes whereby effective global mitigation occurs but the case countries do not participate. Hence, while avoiding mitigation costs, the case countries are able to import fossil fuels at a substantially lower cost.

The combined effect of these two benefits is to shift the distribution of economic outcomes to the right with the mean GDP outcome improving by about two to six percentage points relative to the unconstrained emissions case. For Malawi and Mozambique, mean and mode outcomes are superior to the no climate change baseline. For Zambia (a lower middle-income country), the mean of the distribution of the GDP outcomes is only slightly worse than the no

\footnotetext{
${ }^{7}$ See supplementary appendix B for the particularities of the Mozambique case.

${ }^{8}$ The opposite occurs when oil prices rise. See Arndt et al. (2012b) for a detailed analysis.
} 
a: Mozambique (with legend for all).

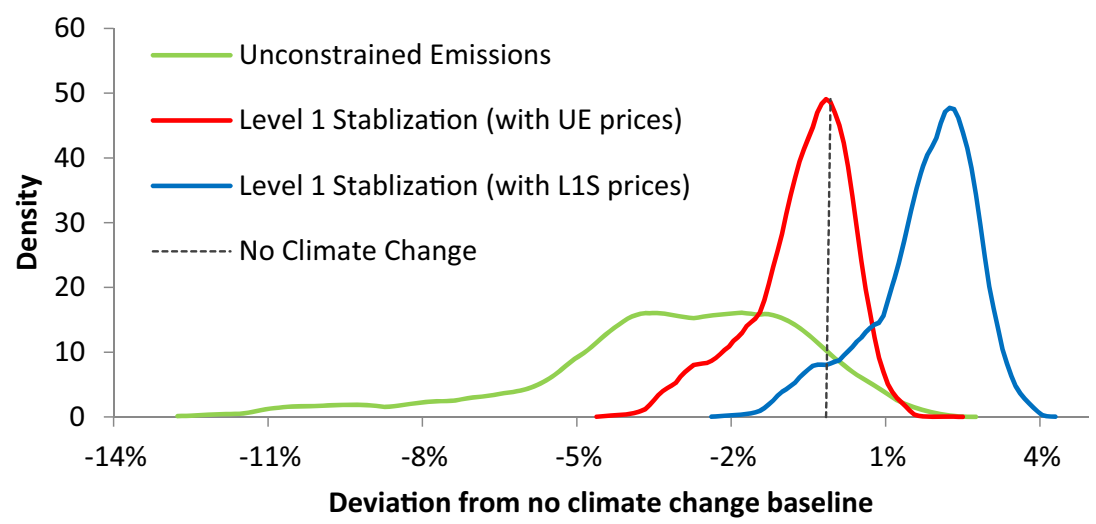

b: Malawi.

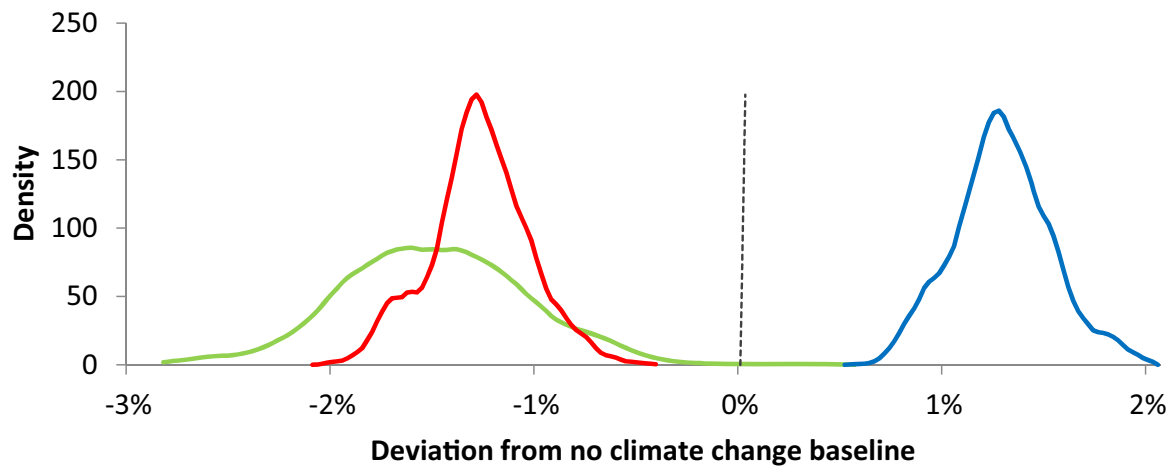

c: Zambia.

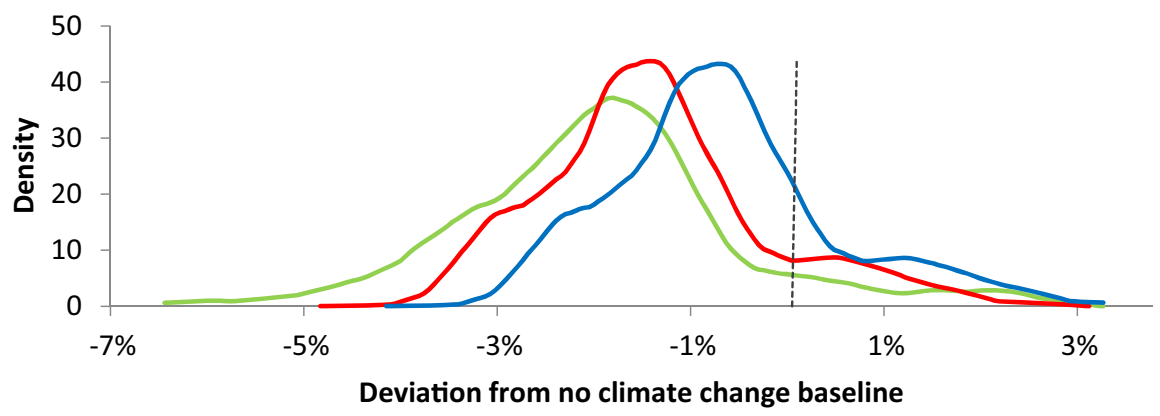

Fig. 5 Effects of global mitigation policy on GDP levels by 2050

climate change baseline with about one fourth of the distribution lying above the no climate change baseline. 


\section{Developing country economic interests}

For the case countries considered, successful global mitigation policies designed to stabilize atmospheric concentrations of greenhouse gases at around $560 \mathrm{ppm} \mathrm{CO} 2 \mathrm{eq}$ generate benefits that are roughly on the order of or greater than the range of costs that have been associated with mitigation policies looking out to about 2050 (Edenhofer et al. 2014; Field et al. 2014). For low-income countries such as Mozambique and Malawi, special and differential treatment in terms of participation in the global mitigation regime can be reasonably assumed to pertain, at least until those countries attain middle-income status. For these two countries and for lowincome countries generally, successful global mitigation, with delayed adherence to a global mitigation regime, may well be preferred to a (fictional) no climate change baseline, even in the absence of any concessionary climate finance. ${ }^{9}$

Zambia, as a lower middle-income country, is likely to be a different case. Given the prominent role of developing countries in emissions growth (Field et al. 2014), middle-income developing countries, including Zambia, are likely to be expected to participate in a global mitigation regime, with implications for growth. Zambia's actual growth trajectory will then also depend on the mitigation options available and the efficiency of its mitigation practices and policies. ${ }^{10}$ Nevertheless, the results presented here imply a degree of space for the case countries to achieve global mitigation objectives and to simultaneously maintain or exceed the growth trajectory under unconstrained emissions.

While the focus has been on the case countries, these are likely to be fairly general results across developing countries. The increases in temperature and shifts in precipitation inherent in climate change appear to be unlikely to be net beneficial to most developing countries even in the relatively near term. In addition, the world price shifts that are highly likely to be inherent in successful global mitigation effectively provide a substantial automatic transfer mechanism to structural fuel importers. This latter result is both quite general, in that the majority of developing countries are large structural fuel importers, and surprisingly unexplored. In essence, the two scenarios considered, UE and L1S, present to most developing countries a choice between (i) generally rising energy import cost burdens (under UE) and (ii) the complexities of undertaking an energy transformation in collaboration, but not necessarily in lockstep, with the rest of the world (in L1S).

With respect to developing countries that are net fossil fuel exporters, their terms of trade will decline. Globally, changes in terms of trade are, essentially, a zero-sum game. Nevertheless, a large literature finds that fossil fuel endowments are frequently a "curse" with respect to GDP growth dynamics in developing countries (Sachs and Warner 2001; Frankel 2010). Hence, world price declines for fossil fuels are not necessarily a bad thing even for the populations of fossil fuel exporters when taking a long-run development perspective.

Why are these fuel price effects so rarely considered? While fossil fuel terms of trade effects are present in mitigation assessments based on models such as EPPA, the implications are often substantially reduced through aggregation. As noted, an aggregate region "sub-Saharan Africa" within a global economy-wide modeling framework is effectively, in economic terms, South Africa with oil. ${ }^{11}$ The results produced here cannot emerge from an aggregate representation of sub-Saharan Africa. For a proper analysis, one needs a tool with the ability to

\footnotetext{
${ }^{9}$ Mozambique's upcoming exploitation of considerable oil and gas reserves substantially complicates these considerations. See supplementary appendix A for more discussion.

${ }^{10}$ Arndt et al. (2016) examine low-cost mitigation options rooted in regional hydropower production.
} 
project global energy markets and prices combined with detailed country-level models, as developed here.

In terms of future research, we note that oil price dynamics and the corresponding changes in terms of trade are challenging to project. For example, the EPPA model employed by Paltsev (2012) and the REMIND model of Bauer et al. (2016) stake out opposite extremes in terms of future expectations. In EPPA, the agent's choices are guided by past outcomes and declared future policy shifts are regarded as non-credible and hence ignored. In REMIND, agents have perfect foresight including with respect to the actual course of policy. Neither extreme is entirely satisfactory, and neither model captures all aspects of strategic behavior in, for example, oil markets. As shown here, fossil fuel price effects of global mitigation have substantial implications for growth and welfare and merit more detailed consideration.

Other modeling challenges also remain on the agenda. Notably, extreme events, such as floods, are both important and challenging to capture faithfully within a model.

Finally, the smooth adjustment mechanisms assumed within many economic models have the potential to underestimate costs of disruption. The economy-wide model employed for this analysis fixes capital stocks in sectors once investment is made and employs adaptive expectations for investment allocation. Unwarranted "smoothness" in temporal adjustment, for example, via perfect foresight, is avoided. Nevertheless, labor moves freely between sectors in accordance with market conditions and total employment is fixed in any given year. This opens the possibility for some underestimation of adjustment costs. How people actually respond to the implications of climate, such as the increase in uncertainty in general and the (hard to forecast) changes in the frequency/severity of extreme events in particular, remain important topics for future research.

Acknowledgments IFPRI and UNU-WIDER gratefully acknowledge support from the Towards Inclusive Economic Growth in Southern Africa (SA-TIED) program. The Joint Program for the Science and Policy of Global Change thanks its sponsors for their ongoing support.

Open Access This article is distributed under the terms of the Creative Commons Attribution 4.0 International License (http://creativecommons.org/licenses/by/4.0/), which permits unrestricted use, distribution, and reproduction in any medium, provided you give appropriate credit to the original author(s) and the source, provide a link to the Creative Commons license, and indicate if changes were made.

\section{References}

Arndt C, Tarp F (2015) Climate change impacts and adaptations: lessons learned from the greater Zambezi river valley and beyond. Clim Chang 130:9-19

Arndt C, Thurlow J (2015) Climate uncertainty and economic development: evaluating the case of Mozambique to 2050. Clim Chang 130:63-75

Arndt C, Chinowsky P, Strzepek K, Thurlow J (2012a) Climate change, growth and infrastructure investment: the case of Mozambique. Rev Devel Econ 16:463-475

Arndt C, Hussain MA, Jones ES, Nhate V, Tarp F, Thurlow J (2012b) Explaining the evolution of poverty: the case of Mozambique. Am J Agric Econ 94(4):854-872

Arndt C, Schlosser CA, Strzepek K, Thurlow J (2014) Climate change and economic growth prospects for Malawi: an uncertainty approach. J Afr Econ 23(4):ii83-ii107

Arndt C, Fant C, Robinson S, Strzepek K (2015) Informed selection of future climates. Clim Chang 130:21-33

\footnotetext{
${ }^{0}$ Sub-Saharan Africa is a net exporter of oil and derived products as measured in the GTAP data that underlies EPPA (as well as many other global economic models).
} 
Arndt C, Davies R, Gabriel S, Makrelov K, Merven B, Hartley F, Thurlow J (2016) A sequential approach to integrated energy modeling in South Africa. Appl Energy 161:591-599

Bauer N, Mouratiadou I, Luderer G, Baumstark L, Brecha RJ, Edenhofer O, Kriegler E (2016) Global fossil energy markets and climate change mitigation-an analysis with REMIND. Clim Chang 136(1):69-82

Carney M (2015) Breaking the tragedy of the horizon - climate change and financial stability. Speech given at Lloyd's of London, September 29. http:/www.bankofengland.co.uk/publications/Pages/speeches/2015/844. aspx

Chinowsky P, Schweikert AE, Strzepek NL, Strzepek K (2015) Infrastructure and climate change: a study of impacts and adaptations in Malawi, Mozambique, and Zambia. Clim Chang 130:49-62

Edenhofer O et al (2014) Climate change 2014: mitigation of climate change. Contribution of working group III to the fifth assessment report of the intergovernmental panel on climate change. Cambridge University Press, Cambridge

Fant C, Gueneau A, Strzepek K, Awadalla S, Farmer W, Blanc E, Schlosser CA (2012) CliCrop: a crop waterstress and irrigation demand model for an integrated global assessment modeling approach. Joint Program on the science and policy of global change, Report 214

Fant C, Gebretsadik Y, McCluskey A, Strzepek K (2015) An uncertainty approach to assessment of climate change impacts on the Zambezi River Basin. Clim Chang 130:35-48

Field CB et al. eds (2014) Climate change 2014: impacts, adaptation, and vulnerability. Part A: global and sectoral aspects. Contribution of Working Group II to the Fifth Assessment Report of the Intergovernmental Panel on Climate Change. Cambridge University Press, Cambridge

Frankel J (2010) The natural resource curse: a survey. John F. Kennedy School of Government, Harvard University RWP10-005

Hasegawa T, Fujimori S, Havlík P, Valin H, Bodirsky BL, Doelman JC et al (2018) Risk of increased food insecurity under stringent global climate change mitigation policy. Nat Clim Chang 8(8):699

Headey, D.D. (2018). Food prices and poverty. The World Bank Economic Review, 32(3): 676-91.

Headey DD, Martin WJ (2016) The impact of food prices on poverty and food security. Ann Rev Resour Econ 8: 329-351

Hertel TW (2015) Food security under climate change. Nat Clim Chang 6(1):10

Hewitson BC, Crane RG (2006) Consensus between GCM climate change projections with empirical downscaling: precipitation downscaling over South Africa. Int J Climatol 26(10):1315-1337

IPCC (2014) Climate change 2014: synthesis report. Contribution of working groups I, II and III to the fifth assessment report of the intergovernmental panel on climate change. IPCC, Geneva

IPCC (2018) Global warming of $1.5^{\circ} \mathrm{C}$. IPCC, Geneva

Kaczmarek Z (1993) Water balance model for climate impact analysis. Acta Geophys Pol 41:1-16

Meehl GA, Covey C, Taylor KE, Delworth T, Stouffer RJ, Latif M, McAvaney B, Mitchell JF (2007) The WCRP CMIP3 multi-model dataset: a new era in climate change research. Bull Am Meteorol Soc 88:1383-1394

Neumann JE, Emanuel KA, Ravela S, Ludwig LC, Verly C (2013) Assessing the risk of cyclone-induced storm surge and sea level rise in Mozambique. UNU-WIDER working paper 2013/036

Paltsev S. (2012) Implications of alternative mitigation policies on world prices for fossil fuels and agricultural products. UNU-WIDER working paper 2012/65

Paltsev S, Reilly JM, Jacoby HD, Eckaus RS, McFarland J, Sarofim M, Asadoorian M, Babiker M (2005) The MIT emissions prediction and policy analysis (EPPA) model: version 4. MIT joint program on the science and policy of global change, Report 125

Sachs JD, Warner AM (2001) The curse of natural resources. Eur Econ Rev 45:827-838

Schlosser CA, Strzepek K (2015) Regional climate change of the greater Zambezi River basin: a hybrid assessment. Clim Chang 130:9-19

Schlosser CA, Gao X, Strzepek K, Sokolov A, Forest CE, Awadalla S, Farmer W (2013) Quantifying the likelihood of regional climate change: a hybridized approach. J Clim 26:3394-3414

Shongwe ME, Van Oldenborgh GJ, Van Den Hurk BJ, De Boer B, Coelho CA, Van Aalst MK (2009) Projected changes in mean and extreme precipitation in Africa under global warming. Part I: southern Africa. J Clim 22(13):3819-3837

Sieber J, Purkey D (2007) User guide for WEAP21. Stockholm Environment Institute, Stockholm

Sokolov AP, Schlosser CA, Dutkiewicz S, Paltsev S, Kicklighter DW, Jacoby HD, Prinn RG, Forest CE, Reilly JM, Wang C, Felzer BS (2005) The MIT Integrated Global System Model (IGSM) version 2: model description and baseline evaluation. MIT Joint Program on the Science and Policy of Global Change Report 124

Webster M, Sokolov AP, Reilly JM, Forest CE, Paltsev S, Schlosser A, Wang C, Kicklighter D, Sarofim M, Melillo J, Prinn RG (2012) Analysis of climate policy targets under uncertainty. Clim Chang 112:569-583

Publisher's note Springer Nature remains neutral with regard to jurisdictional claims in published maps and institutional affiliations. 


\section{Affiliations}

\section{Channing Arndt ${ }^{1} \cdot$ Paul Chinowsky ${ }^{2} \cdot$ Charles Fant $^{3} \cdot$ Sergey Paltsev ${ }^{4}$ - C. Adam} Schlosser ${ }^{4} \cdot$ Kenneth Strzepek ${ }^{4}$ - Finn Tarp ${ }^{5} \cdot$ James Thurlow $^{6}$

Paul Chinowsky

paul.chinowsky@colorado.edu

Charles Fant

chasfant@gmail.com

Sergey Paltsev

paltsev@mit.edu

C. Adam Schlosser

casch@mit.edu

Kenneth Strzepek

Strzepek@mit.edu

Finn Tarp

finn@wider.unu.edu

James Thurlow

j.thurlow@cgiar.org

1 Environment and Production Technology Division, International Food Policy Research Institute, 1201 Eye St. NW, Washington, DC 20005, USA

2 Civil Systems, Environmental and Architectural Engineering, University of Colorado at Boulder, UCB 428, Boulder, CO 80309-0428, USA

3 Industrial Economics Inc., 2067 Massachusetts Ave, Cambridge, MA 02140, USA

4 Joint Program on the Science and Policy of Global Change, MIT, 77 Massachusetts Ave, E19-429F, Cambridge, MA 02139-4307, USA

5 World Institute for Development Economics Research, United Nations University, Katajanokanlaituri 6 B, FI-00160 Helsinki, Finland

6 Development Strategies and Governance Division, International Food Policy Research Institute, 1201 Eye St. NW, Washington, DC 20005, USA 